\title{
INFLUÊNCIA DAS CULTURAS LÁTICAS NO ÍNDICE DE PROTEÓLISE DO QUEIJO MINAS FRESCAL ${ }^{1}$
}

\author{
J.S. ISEPON \\ Departamento de Horticultura e Tecnologia de Alimentos-FE/UNESP, CEP: 15378-000-Ilha Solteira,SP. \\ A.J. OLIVEIRA \\ Departamento de Ciência e Tecnologia Agroindustrial - ESALQ/USP, C.P. 9, CEP: 13418-900 - Piracicaba,SP.
}

\begin{abstract}
RESUMO: Estudou-se, a influência de culturas láticas no índice de protéblise do queijo Minas Frescal, processado com leite não pasteurizado e pasteurizado. $O$ emprego de culturas láticas na elaboração de queijo Minas Frescal pode ser indicado, uma vez que o'índice de protéblise só se correlacionou com o tempo de conservação.

Descritores: queijo Minas Frescal, culturas láticas, índice de proteólise.
\end{abstract}

\section{THE INFLUENCE OF LACTIC CULTURES IN THE RIPENING INDEX OF MINAS FRESCAL CHEESE}

\begin{abstract}
The influence of lactic cultures in the ripening index of Minas Frescal cheese was studied, utilizing pasteurized and not pasteurized milk. The use of lactic cultures for Minas Frescal cheese can be recomended, since the ripening index had good correlation only with storage time.

Key Words: Minas Frescal cheese, lactic cultures, ripening index.
\end{abstract}

\section{INTRODUÇÃO}

A fabricação do queijo Minas Frescal tem uma tecnologia das mais simples e, por isso, muito difundida. Com a evolução das técnicas industriais e do conhecimento científico, a tecnologia de fabricação sofreu modificações visando a melhoria da qualidade do produto, aumento do rendimento de fabricação ou ainda maior padronização do produto final (FURTADO et al., 1980).

Os estreptococos láticos são amplamente utilizados pela indústria laticinista como componentes do fermento lático para os mais diversos tipos de queijos, onde são responsáveis por características e/ou textura da massa, e na produção de diferentes tipos de leite fermentados (COX, 1977 e SHARPE, 1979). Para SHERWOOD \& WHITEHEAD (1934), os estreptococos parecem ter pequena influência na proteólise dos queijos, durante a maturação e concluiram que a ação mais importante destas bactérias é a formação de acidez, que facilita a ação enzimática do coalho. Entretanto, DAVIS et al. (1937), verificaram que tanto o coalho como as bactérias láticas são capazes de degradar a proteína do leite. A proteólise nos queijos fabricados com bactérias láticas é lenta no início, e em seguida aumenta rapidamente, para no final declinar, sendo que este aumento deve-se ao aumento da atividade total das enzimas bacterianas liberadas após a autólise das bactérias (GREEN \& FOSTER, 1974).

O objetivo do presente trabalho foi o de verificar o efeito da adição das culturas láticas no índice de proteólise no queijo Minas Frescal, processados com leite não pasteurizado $\mathrm{e}$ pasteurizado nos dias zero, 5,9 e 13 , armazenados à temperatura de $5,0 \pm 1,0^{\circ} \mathrm{C}$.

\section{MATERIAL E MÉTODOS}

Foram utilizadas as seguintes matérias primas:

1) Leite integral não pasteurizado, produzido pelo rebanho do Departamento de Zootecnia, da Escola Superior de Agricultura "Luiz de Queiroz";

2) Leite pasteurizado, adquirido no comércio local de Piracicaba-SP.

\footnotetext{
1 Parte da dissertação de Mestrado apresentada pelo primeiro autor à Faculdade de Ciências Farmacêuticas/USP, em 1989.
} 
Foram instalados os seguintes
tratamentos:

Tratamento A: sem adição de cultura lática;

Tratamento B: adição de $1,0 \%$ de cultura lática Lactococcus lactis spp. lactis (cultura $\mathrm{n}^{\circ} 302-\mathrm{C} 2$ Lact Strept R);

Tratamento C: adição de $1,0 \%$ de cultura lática, sendo $0,5 \%$ de Lactococcus lactis spp. lactis e de $0,5 \%$ de Lactococcus lactis spp. cremoris (cultura $n^{\circ} 03$ - C. Hansen's).

As culturas láticas foram adquiridas da Seção de Leite e Derivados do Instituto de Tecnologia de Alimentos (ITAL). A tecnologia de fabricação do queijo Minas Frescal foi a indicada pelo Instituto de Laticínios "Cândido Tostes", segundo VIEIRA \& LOURENÇO (1982), e desenvolvida no Laboratório do Departamento de Ciência e Tecnologia Agroindustrial da Escola Superior de Agricultura "Luiz de Queiroz"/USP, localizada no município de Piracicaba,SP.

De cada lote de fabricação foram retiradas amostras após zero, 5,9 e 13 dias, e analisadas para as seguintes análises físicoquímicas:

1) $\mathrm{pH}$ foi determinado pelo método recomendado pelo LANARA (1981). A leitura foi efetuada após 30 minutos, utilizando-se um potenciômetro com eletrodo de vidro, marca Digimed, modelo DMPH2;

2) Ácido lático e nitrogênio total foi determinado pelo método recomendado pela A.O.A.C. (1975);

3) Nitrogênio solúvel foi determinado segundo SCHIMIDT-HEBBEL (1956).

4) Indice de proteólise (\% de nitrogênio solúvel em relação ao nitrogênio total) foi calculado pela fórmula proposta por SCHIMIDT-HEBBEL(1956).

Todos os resultados foram submetidos à análise estatística: o delineamento experimental adotado foi 0 inteiramente casualizado, num esquema fatorial $3 \times 2 \times 4$, que se constitui de 3 tipos de cultura (sem cultura, Lactococcus lactis spp. lactis e Lactococcus lactis spp. lactis + Lactococcus lactis spp. cremoris), 2 tipos de leite (leite integral não pasteurizado e pasteurizado) e 4 tempos (zero, 5, 9 e 13 dias após o processamento). Para se constatar diferenças entre as médias foi utilizado o teste de Tukey a $5 \%$ de probabilidade (PIMENTEL GOMES, 1985).

Também foi feita análise de correlação entre os parâmetros: tempo de armazenamento, \% de ácido lático, $\mathrm{pH}, \%$ de nitrogênio solúvel $\mathrm{e}$ índice de protélise (HOFFMAN \& VIEIRA, 1977).

\section{RESULTADOS E DISCUSSÃO}

A determinação do índice de proteólise tem sido comumente utilizado na verificação da degradação protéica em queijos (WOLFSCHOONPOMBO, 1983). Segundo FURTADO \& LOURENÇO (1979) o acompanhamento destes dados em um queijo permite conhecer o indice de aproveitamento do leite na coalhada, a atividade proteolítica do coalho e fermento, bem como o momento ideal de lançamento do queijo no mercado.

A TABELA 1 mostra $o$ índice de proteólise calculado para o queijo Minas Frescal, processado com leite não pasteurizado e pasteurizado durante o armazenamento a $5,0^{\circ} \mathrm{C} \pm$ $1,0^{\circ} \mathrm{C}$. Observando os dados da TABELA 1 , vê-se que $o$ índice de proteólise aumentou significativamente à medida que se aumentou o tempo de conservação no leite não pasteurizado e pasteurizado, com as médias variando de 4,55 a 11,01 e 4,64 a 10,71, respectivamente, no queijo. Os resultados observados no presente trabalho concordam aos verificados por BONASSI (1979), que foram de 8,07 a 10,61 no queijo, por ROGIGK (1944), que foram de 7,0 determinados em quejo Minas e por WOLFSCHOON-POMBO (1983) que, trabalhando com Minas Frescal, verificou valores médios de 7,8 a 10,40 em queijos processados com adição de fermento lático, e de 5,8 a $9,7 \mathrm{em}$ queijos cujo leite foi acidificado com ácido lático.

Os coeficientes de correlação do índice de proté́lise avaliado em função do tempo de armazenamento, $\mathrm{pH}$, ácido lático e nitrogênio solúvel, constam da TABELA 2. Observando-se esses dados, vê-se que existe uma interação entre os diversos parâmetros estudados nos diferentes tratamentos empregados.

Verifica-se que em todos os tratamentos com leite não pasteurizado houve uma correlação altamente significativa entre índice de proté́lise e os demais parâmetros estudados. Observa-se que a cultura lática adicionada não influenciou na correlação. 
TABELA 1 - Índice de Proteólise (relação de NS/NT x 100), calculado em relação ao queijo. Média de 6 repetições.

\begin{tabular}{|c|c|c|c|c|c|c|c|c|}
\hline \multirow{2}{*}{$\begin{array}{l}\text { Tipo de leite } \\
\text { Tempo de } \\
\text { Armazenamento (dias) }\end{array}$} & \multicolumn{4}{|c|}{ Não pasteurizado } & \multicolumn{4}{|c|}{ Pasteurizado } \\
\hline & 0 & 5 & 9 & 13 & 0 & 5 & 9 & 13 \\
\hline \multicolumn{9}{|l|}{ Tratamentos } \\
\hline - sem culturas & 5,20 & 6,18 & 7,34 & 8,77 & 4,99 & 7,93 & 9,03 & 10,71 \\
\hline $\begin{array}{l}1 \% \text { de L. lactis spp. } \\
\text { lactis }\end{array}$ & 4,55 & 6,52 & 8,55 & 10,19 & 4,64 & 7,80 & 9,48 & 10,53 \\
\hline \multicolumn{9}{|l|}{$\begin{array}{l}1 \% \text { de L. lactis spp. } \\
\text { lactis }+\end{array}$} \\
\hline L. lactis spp. cremoris & 4,68 & 7,94 & 9,79 & 11,01 & 4,69 & 7,44 & 9,03 & 10,55 \\
\hline
\end{tabular}

TABELA 2 - Coeficientes de correlação do índice de proteólise avaliados em função do tempo de armazenamento, pH, ácido lático e nitrogênio solúvel.

\begin{tabular}{|c|c|c|c|c|c|c|}
\hline \multirow{2}{*}{$\begin{array}{l}\text { Tipo de leite } \\
\text { Tratamentos }\end{array}$} & \multicolumn{3}{|c|}{ Não pasteurizado } & \multicolumn{3}{|c|}{ Pasteurizado } \\
\hline & $\begin{array}{c}\text { sem } \\
\text { cultura }\end{array}$ & $\begin{array}{c}1 \% \\
\text { L.lactis } \\
\text { spp lactis }\end{array}$ & $\begin{array}{c}1 \% \text { L.lactis spp } \\
\text { lactis + L.lactis } \\
\text { spp cremoris }\end{array}$ & $\begin{array}{c}\text { sem } \\
\text { cultura }\end{array}$ & $\begin{array}{c}1 \% \\
\text { L.lactis } \\
\text { spp lactis }\end{array}$ & $\begin{array}{c}1 \% \text { L.lactis spp } \\
\text { lactis + L.lactis } \\
\text { spp cremoris }\end{array}$ \\
\hline \multicolumn{7}{|l|}{ Parâmetros } \\
\hline Tempo & $0,996 * *$ & $0,998^{* *}$ & $0,976^{* *}$ & $0,980^{*}$ & $0,970^{*}$ & $0,988 *$ \\
\hline $\mathrm{pH}$ & $-0,991 * *$ & $-0,994 * *$ & $-0,998 * *$ & $-0,989 * *$ & $-0,993 * *$ & $-0,986 * *$ \\
\hline Ác. lático (\%) & $0,992^{* *}$ & $0,996 * *$ & $0,994^{* *}$ & $0,935^{\text {ss }}$ & $0,996 * *$ & $0,981 *$ \\
\hline Nit. solúvel (\%) & $0,993^{* *}$ & $0,999 * *$ & $0,998^{* *}$ & $0,998^{* *}$ & $0,999 * *$ & $0,999 * *$ \\
\hline I. Proteólise & 1,00 & 1,00 & 1,00 & 1,00 & 1,00 & 1,00 \\
\hline
\end{tabular}

** significativo a $1,0 \% ; *$ significativo a $5 \% ;$ n.s. = não significativo

Isto pode estar relacionado com o tipo de flora microbiana existente no leite, porque diferenças são encontradas na maneira com que as espécies se desenvolvem na presença do $L$. lactis spp. lactis ou $L$. lactis spp. cremoris; sendo que algumas são compatíveis ou não. Verifica-se que quando se utilizou leite pasteurizado a significância das correlações foram diferenciadas entre tratamento. A cultura lática influenciou na produção de ácido lático. No tratamento que não se adicionou cultura lática, a produção de ácido lático não foi significativa, já no tratamento com $1,0 \%$ de L. lactis spp. lactis foi altamente significativa, quando comparada com $1,0 \%$ de $L$. lactis spp. lactis $+L$. lactis spp. cremoris que foi significativa, somente a $5,0 \%$.

Estas diferenças podem estar relacionadas com o tipo de cultura utilizada. $O$ L. lactis spp. lactis em média produz mais ácido lático e é mais tolerante às variações de temperatura, quando comparado com o $\boldsymbol{L}$. lactis spp. cremoris. 


\section{CONCLUSÕES}

Pode-se concluir que o tempo de conservação influenciou significativamente no índice de proteólise do queijo Minas Frescal, tanto quando se empregou leite pasteurizado ou não pasteurizado.

O emprego das culturas láticas na elaboração de queijo Minas Frescal pode ser indicado, uma vez que o índice de proteólise só se correlacionou com o tempo de conservação.

\section{REFERÊNCIAS BIBLIOGRÁFICAS}

ASSOCIATION OF OFFICIAL ANALYTICAL CHEMISTS. Official methods of analysis. 12.ed. Washington, 1975. $1094 \mathrm{p}$.

BONASSI, I.A. Influência de algumas espécies de bactérias láticas na elaboração do queijo tipo Minas. Botucatu, 1979. 133p. Tese (Livre-Docência)Faculdade de Ciências Agronômicas/ UNESP).

COX, W.A. Characteristics and use of starter cultures in the manufature of hard processed cheese. Journal Dairy Technology, London, v.30, n.1, p.15-25, 1977.

DAVIS, J.G.; DAVIES, W.L.; MATTICK, A.T.R. Studies in cheddar chesse. VI. The degradation of milk protein by lactic acid bacteria isolated from cheese, alone, with sterile rennet and with whole rennet. Journal Dairy Technology, London, v.8, p.238-244, 1937.

FURTADO, M.M. \& LOURENÇO NETO, J.P.M. Estudo rápido sobre a composição média dos queijos Prato e Minas no mercado. Boletim do Leite. Rio de Janeiro, n.605, p.4-38, 1979.

FURTADO, M.M.; SOUZA, H.M.; MUNCH, A.V.A. Fabricação do queijo Minas Frescal sem emprego de culturas láticas. Revista do Instituto de Laticínios "Cândido Tostes", Juiz de Fora, v.207, n.35, p.15-21, 1980.

Sci. agric., Piracicaba, 50(3):451-454, out./dez., 1993
GREEN, M.L. \& FOSTER, P.M.B. Comparation of the rates of proteolysis during ripening of cheddar cheese mad with calf rennet and swine pepsin as coagulants. Journal Dairy Technology, London, v.41, n.2, p.269-282, 1974 .

HOFFMAN, R. \& VIEIRA, S. Análise de regressão: uma introdução à econometria. São Paulo: HUCITEC/EDUSP, 1977. 340p.

LANARA. Métodos analíticos oficiais para controle de produtos de origem animal e seus ingredientes. II. Métodos Físicos e Químicos. Brasilia: Ministério da Agricultura, 1981 , p.164.

PIMENTEL GOMES, F. Curso de Estatística Experimental. 11.ed., Piracicaba, 1985. 466p.

ROGIGK, F.A. Estudo sobre a tecnologia do queijo Minas. Boletim da Indústria Animal, São Paulo, v.7, n.3/4, p.81-98, 1944.

SCHMIDT-HEBBEL, H. Alimentos proteicos: queso. Quimica y Tecnologia de los alimentos. Santiago do Chile, Salesiana, 1956. cap.3, p.52-56.

SHARPE, M.E. Lactic acid bacteria in the dairy industry. Joumal Dairy Technology, Paris, v.32, n. I, p.9-18, 1979.

SHERWOOD, I.R. \& WHITEHEAD, H.R. The influence of Streptococcus lactis on the ripening of cheddar cheese. Journal Dairy Technology, Paris. v.5, n.3, p.208-222, 1934 .

VIEIRA, S.D.A. \& LOURENÇO NETO, J.P.M. Elaboração de queijos frescais em pequena escala. Informe Agropecuário, Belo Horizonte, v.8, n.88, p.28-29, 1982

WOLFSCHOON-POMBO, A.F. Índice de proteólise em alguns queijos brasileiros. Boletim do Leite, Rio de Janeiro, n.661, p.1-8, 1983.

Enviado para publicação em 21.08 .92

Aceito para publicação em 05.10 .93 